\title{
Drought reduces tree growing season length but increases nitrogen re- sorption efficiency in a Mediterranean ecosystem
}

\section{Raquel Lobo-do-Vale et al.}

Correspondence to: Raquel Lobo-do-Vale (raquelvale@isa.ulisboa.pt)

The copyright of individual parts of the supplement might differ from the CC BY 4.0 License. 


\section{Supplemental material}

Table S1. Meteorological conditions

\begin{tabular}{|l|ccc|ccc|}
\cline { 2 - 7 } \multicolumn{1}{c|}{} & \multicolumn{3}{c|}{ Temperature (o C) } & \multicolumn{3}{c|}{ Precipitation (mm) } \\
\cline { 2 - 7 } \multicolumn{1}{c|}{} & $1971-2000$ & 2004 & 2005 & $1971-2000$ & 2004 & 2005 \\
\hline Autumn & 13.5 & 12.6 & 12.0 & 249 & 331 & 277 \\
Winter & 10.7 & 10.0 & 7.1 & 187 & 198 & 51 \\
Spring & 16.6 & 18.3 & 18.5 & 98 & 51 & 78 \\
Summer & 22.6 & 24.1 & 23.9 & 45 & 26 & 4 \\
\hline Year & 15.9 & 16.3 & 15.3 & 579 & 607 & 410 \\
\hline
\end{tabular}

Table S2. Timings of the different phenophases (DOY or number of days for duration) and statistical significance between years ( $p$-value).

\begin{tabular}{|c|c|c|c|c|c|c|c|}
\hline \multirow[b]{2}{*}{ Timings } & \multicolumn{3}{|c|}{ Mild year (2004) } & \multicolumn{4}{|c|}{ Dry year (2005) } \\
\hline & Min & Max & Mean \pm SE & Min & Max & Mean \pm SE & $\mathrm{p}$-value \\
\hline \multicolumn{8}{|l|}{ Bud development } \\
\hline Bud active & 78 & 104 & $89 \pm 2$ & 90 & 112 & $105 \pm 2$ & $<0.0001$ \\
\hline Budburst & 97 & 118 & $107 \pm 2$ & 112 & 132 & $120 \pm 2$ & $<0.0001$ \\
\hline Duration & 4 & 32 & $18 \pm 2$ & 5 & 29 & $16 \pm 2$ & 0.258 \\
\hline \multicolumn{8}{|l|}{ Shoot elongation } \\
\hline Onset & 97 & 125 & $108 \pm 2$ & 112 & 132 & $121 \pm 2$ & $<0.0001$ \\
\hline Cessation & 169 & 181 & $175 \pm 2$ & 132 & 153 & $145 \pm 2$ & $<0.0001$ \\
\hline Duration & 44 & 77 & $66 \pm 2$ & 8 & 36 & $24 \pm 2$ & $<0.0001$ \\
\hline \multicolumn{8}{|l|}{ Trunk growth } \\
\hline Onset & 78 & 111 & $93 \pm 3$ & 90 & 103 & $96 \pm 2$ & 0.135 \\
\hline Cessation & 181 & 181 & $181 \pm 0$ & 153 & 153 & $153 \pm 0$ & $<0.0001$ \\
\hline Duration & 70 & 103 & $88 \pm 3$ & 50 & 63 & $57 \pm 2$ & $<0.0001$ \\
\hline Growing season length & 77 & 103 & $92 \pm 2$ & 41 & 63 & $48 \pm 2$ & $<0.0001$ \\
\hline \multicolumn{8}{|c|}{ Leaf senescence } \\
\hline Onset & 91 & 97 & $95 \pm 1.3$ & 103 & 103 & $103 \pm 0$ & 0.031 \\
\hline Cessation & 147 & 153 & $149 \pm 1.3$ & 181 & 181 & $181 \pm 0$ & 0.031 \\
\hline Duration & 50 & 56 & $54 \pm 1.3$ & 78 & 78 & $78 \pm 0$ & 0.031 \\
\hline
\end{tabular}




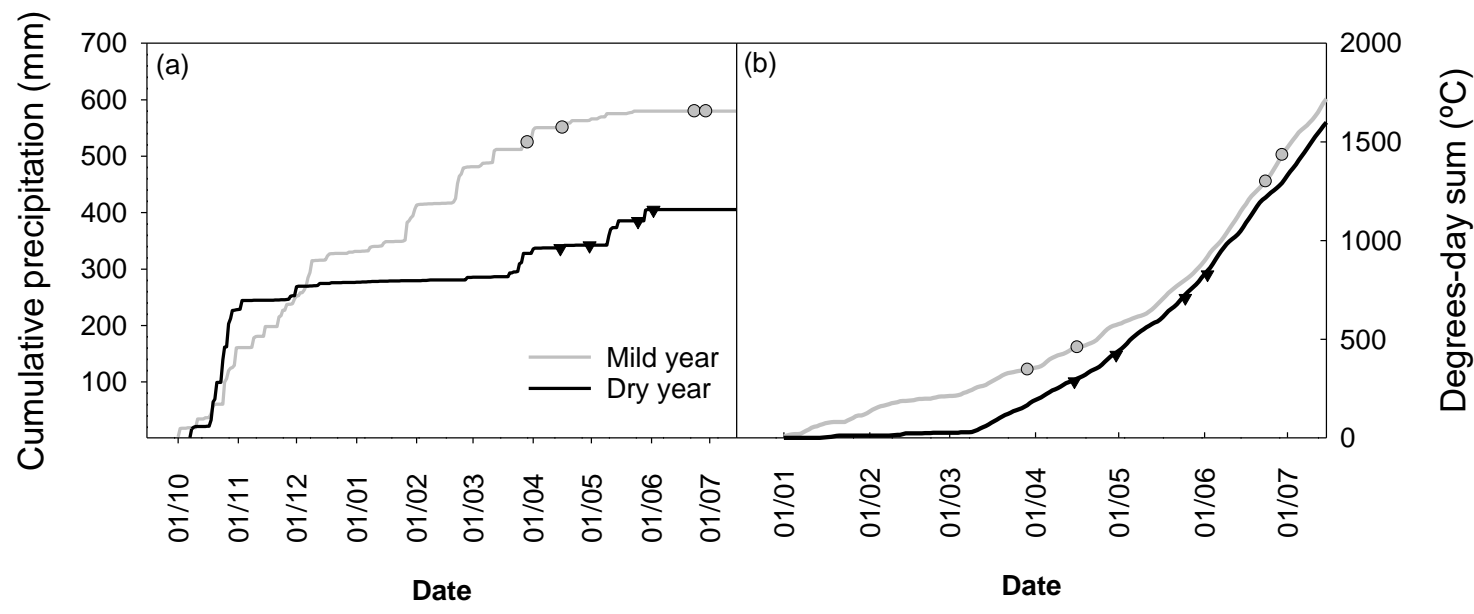

Figure S1. (a) Cumulative precipitation $(\mathrm{mm})$ and (b) degrees-day sum (으) until the end of the growing season. Symbols represent sequentially the mean days of bud activation, bud burst, shoot cessation and trunk cessation.
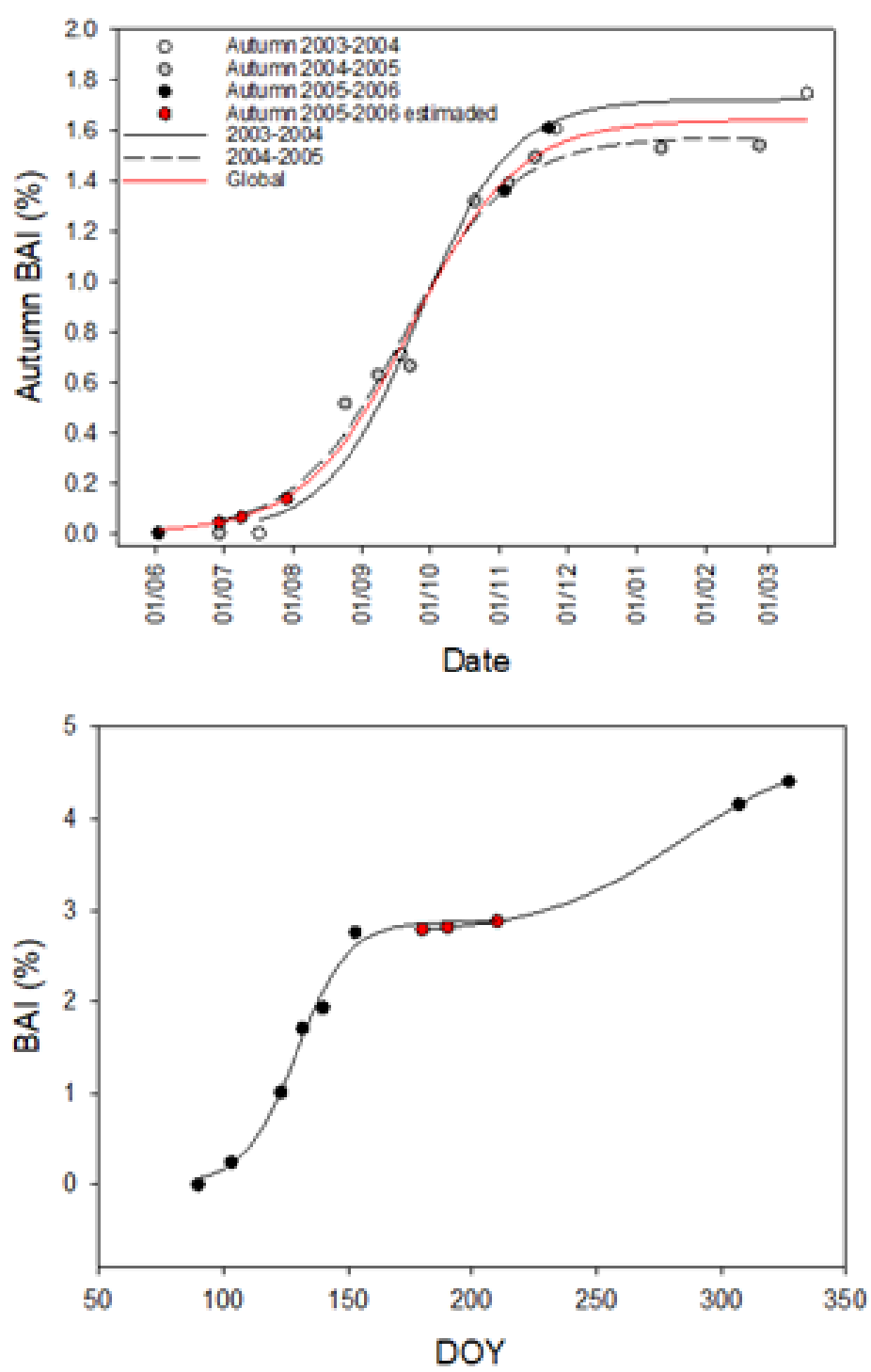

Figure S2. BAl estimation at the end of the growing season of the dry year. (a) Autumn BAI (\%). (b) Overall pattern of BAI (\%) in the dry year. Autumn BAI was considered since dbh increments were lower than $0.05 \%$ day $^{-1}$ until the next spring growth. BAl showed a sigmoidal pattern over time and significant regressions were obtained for each year $(p<0.0001)$. Since the slopes were similar, data was pooled and a general curve (red line) was obtained $(f=a /(1+\exp (-(x-$ $\mathrm{x} 0) / \mathrm{b}))$, where $a=1.6434$, $b=23.7431$ and $x_{0}=262.9882 ; x_{0}$ is DOY). Basal area increments were then estimated to confirm the end of spring trunk growing season. The overall pattern of BAl resulted clearly in the combination of two distinct growing periods, spring and autumn. 


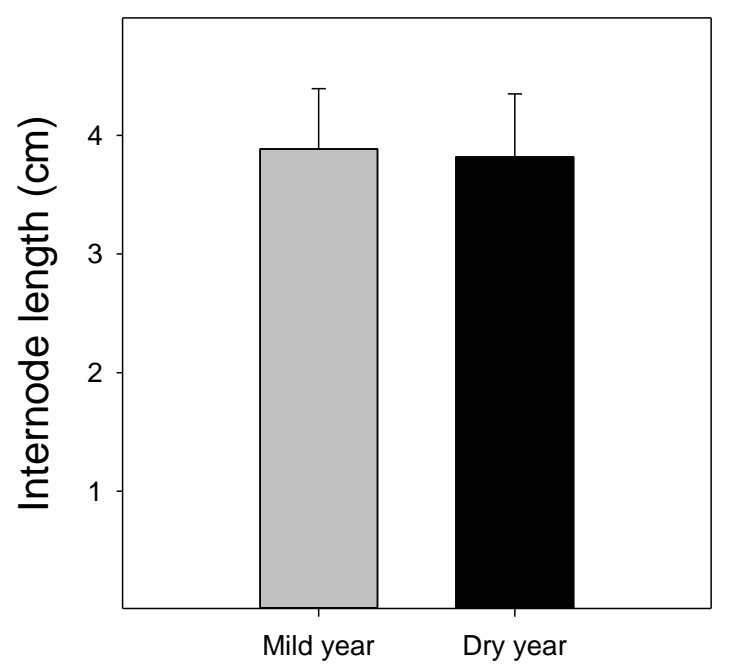

Figure S3. Internode length $(\mathrm{cm})$ obtained as the ratio between shoot length and number of leaves in the two studied years.

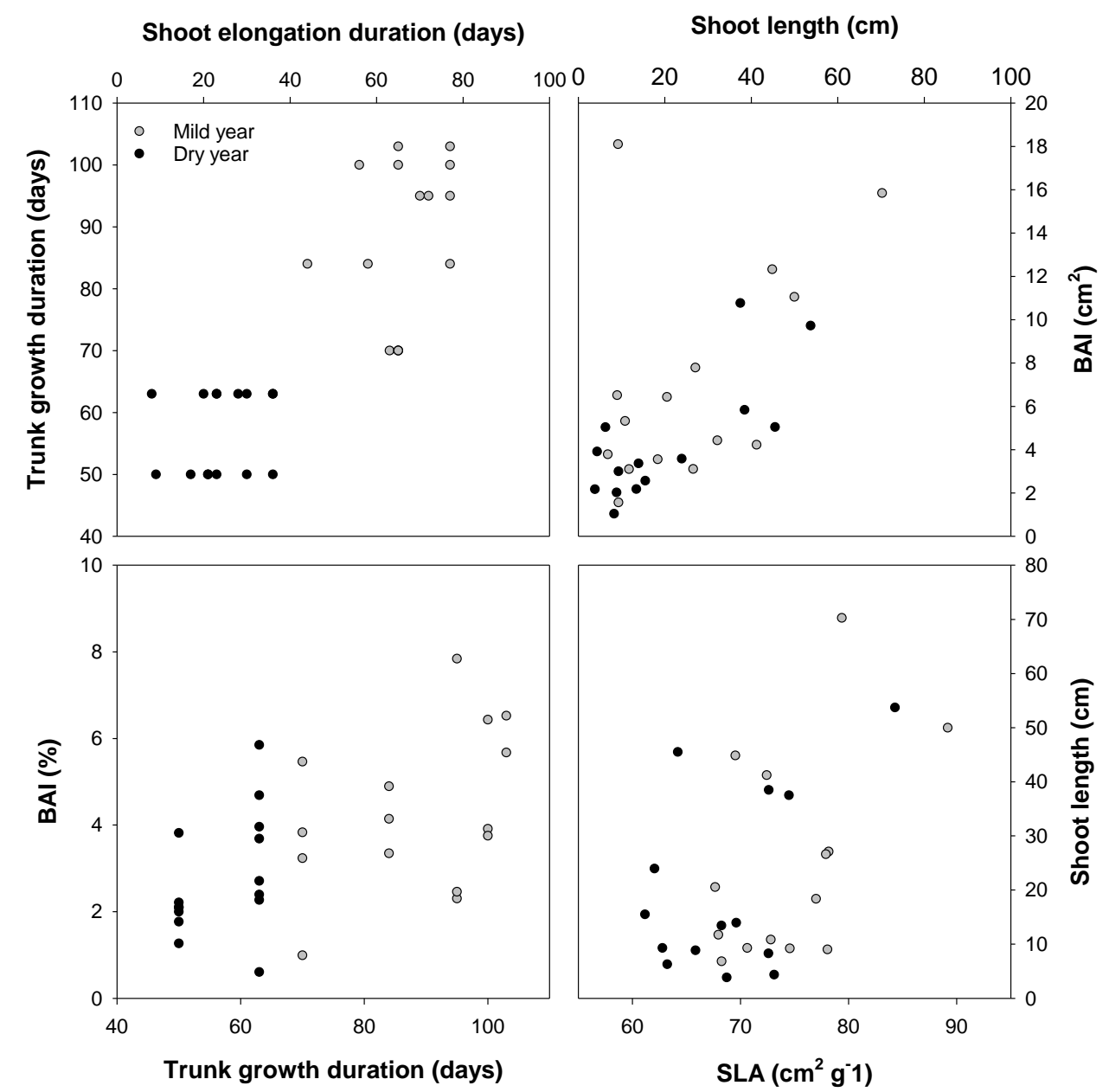

Figure S4. Some correlations between growth variables. 


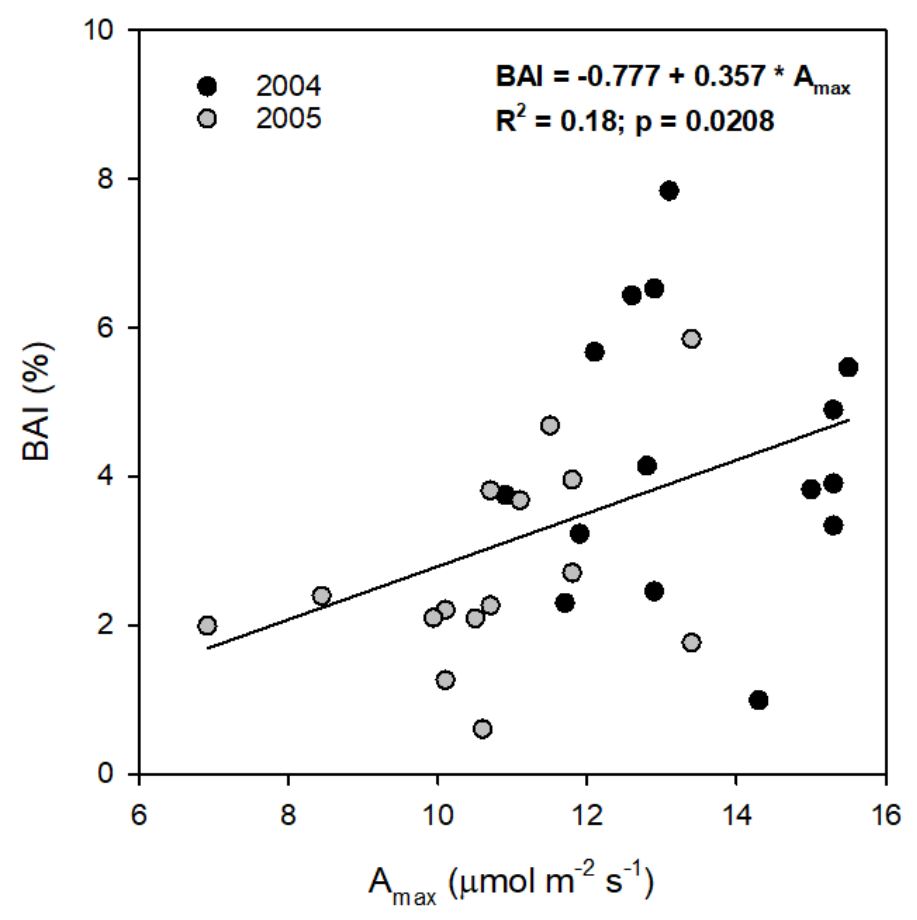

Figure S5. Relationship between carbon assimilation $\left(A_{\max }\right)$ at the onset of the growing season (March) and BAI (\%).

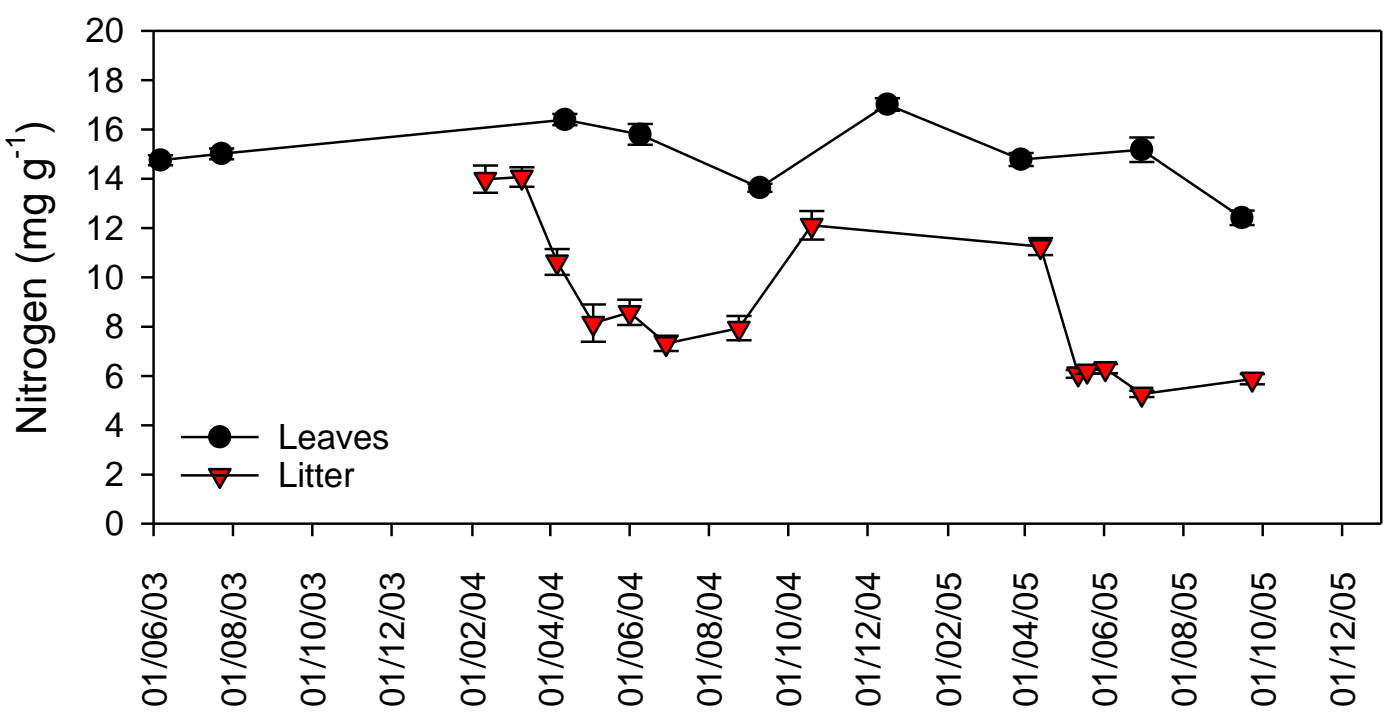

Figure S6. Nitrogen dynamics in green and senescent leaves (litter leaves) over the study period. 


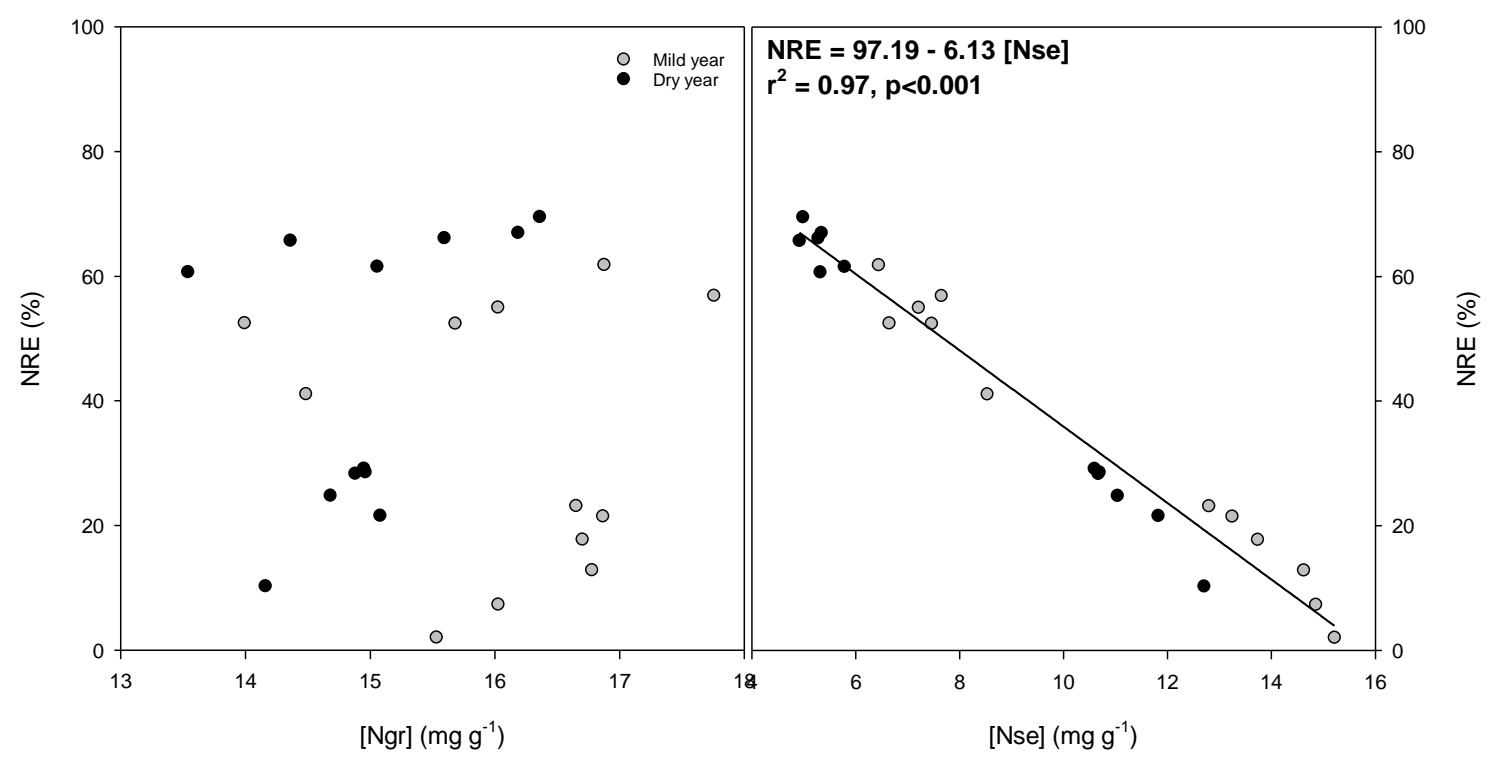

Figure S7. Relationships between Nitrogen resorption efficiency (NRE) and (a) N concentration in green [Ngr] and (b) senescent leaves [Nse].

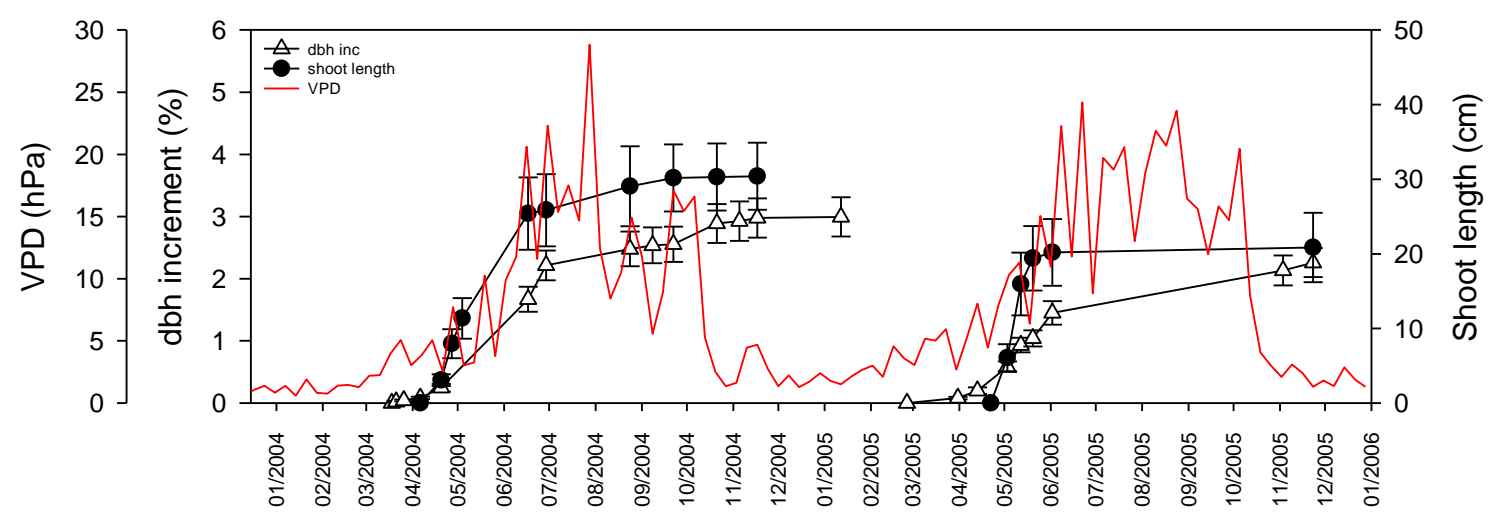

Figure S8. Vapour pressure deficit (VPD, hPa), dbh increment (\%) and shoot length $(\mathrm{cm})$ in the mild year (2004) and in the dry year (2005). VPD is the average of the previous 7 days. 